\title{
COMPARATIVE ANALYSIS OF ORAL HEALTH OUTCOMES FOR FIVE-YEAR-OLD CHILDREN (SOHO-5) SCALE AND EARLY CHILDHOOD ORAL HEALTH IMPACT SCALE (ECOHIS) IN CHILEAN'S PRESCHOOLERS
}

\author{
Valeria Campos' ${ }^{1}$ Carla Bastías², Marcos Orellana², Karen Sáez², Ricardo A. Cartes-Velásquez ${ }^{3}$ \\ 'School of Health Sciences, Universidad Autónoma de Chile, Chile \\ ${ }^{2} S$ chool of Dentistry, Universidad Bolivariana, Chile \\ ${ }^{3}$ Department of Public Health, Fundación Kimntrum, Chile
}

\begin{abstract}
INTRODUCTION: Scale of oral health outcomes for five-year-old children (SOHO-5) and early childhood oral health impact scale (ECOHIS) has been validated for Chilean population; however, there is no clarity which scale has a better performance and discriminant validity for caries.

ОвJестіves: The aim of this study was to compare SOHO-5 (parental version and child's self-reports) and ECOHIS in a sample of Chilean preschoolers.

MATERIAl AND MEthods: 121 pairs were selected from the Pablo Neruda School in Curanilahue, Chile. Collection of dmft/DMFT indices, socio-demographic data, and application of instruments were performed in the facilities of the school. Parents answered ECOHIS and SOHO-5p (parental version), and children answered SOHO-5c (child's self-reports). Mann-Whitney $U$ test and Spearman's correlation coefficients were used for statistical analysis.

RESULTS: SOHO-5p and ECOHIS were strongly correlated. Moreover, SOHO-5p and ECOHIS could discriminate between preschoolers with and without severe caries. In contrast, $\mathrm{SOHO}-5 \mathrm{c}$ did not correlated with SOHO-5p, nor ECOHIS. In addition, SOHO-5c could not distinguish between the presence and absence of severe caries among the sample.

ConcLUSIONS: ECOHIS and SOHO-5p were both significantly correlated with OHRQoL among preschoolers. However, SOHO- $5 \mathrm{c}$ did not correlate with any of the variables studied, nor with SOHO-p or ECOHIS. ECOHIS showed a greater discrimination with the oral health status of preschoolers, as measured by the presence of severe caries.
\end{abstract}

KEY wORDS: ECOHIS, SOHO-5, oral health, quality of life, children.

J Stoma 2021; 74, 2: 110-115

DOI: https://doi.org/10.5114/jos.2021.106262

\section{INTRODUCTION}

Different standardized instruments have been developed and validated to measure oral health-related quality of life (OHRQoL) [1-5]. OHRQoL is obtained from the analysis of responses of the individuals that contemplates different dimensions. Most of these instruments applied are designed according to psychometric model, which is based on the ability of a subject to discern between stimuli of different intensity. For this, target ques-
JOURNAL OF STOMATOLOGY CZASOPISMO STOMATOLOGICZNE
Address for correspondence: Dr. Valeria Campos, Facultad de Ciencias de la Salud, Universidad Autónoma de Chile, Av. Alemania \#1090, Temuco, Chile, postal code: 4810101 , phone: +56412204195 , e-mail: valeriacamposcannobbio@gmail.com ReCEIVED: 11.11.2020 • ACCEPTED: 25.03.2021 • PUBLISHED: 04.06.2021 
tions are generated that point to a specific stimulus, where the person then will respond through a scale of values, which will be subsequently ordered and analyzed [6-9].

Generally, OHRQoL instruments are specifically age-related, as oral health is strongly age-dependent [10]. Therefore, the development of instruments to assess the impact of oral health on children's quality of life has been developed or adapted to this specific group [3, 5, 10-12]. Among these, early childhood oral health impact scale (ECOHIS) has been developed to be administered to parents and caregivers of preschool children. This scale has been authorized in different countries and languages [3, 13-17] and has proven to provide valid and reliable information on the OHRQoL of preschool children [18]. Scale of oral health outcomes for five-yearold children (SOHO-5) was developed based on evidence that children aged four to six years can reliably report quality of life on their own, where the preschool and the parent or caregiver answer the questions [5]. This scale has been also validated in different languages [19-23].

Even though both scales have been widely used, Barbosa et al. concluded that there is a positive correlation between ECOHIS, SOHO-5 parents, and caries; however, SOHO-5 children did not correlate to any of the variables included [24]. Currently, ECOHIS and SOHO-5 has been authenticated for Chilean population, although there is no clarity which of the scale has a better performance and discriminant validity for caries.

\section{OBJECTIVES}

Therefore, the aim of this study was to compare the SOHO-5 (parental version and child's self-reports) and the ECOHIS in a sample of Chilean preschoolers.

\section{MATERIAL AND METHODS}

\section{STUDY DESIGN AND PARTICIPANTS}

This was a cross-sectional study, including 148 preschool children and their parents or caregivers from the Pablo Neruda E-776 School in Curanilahue, province of Arauco, Chile. Illiterate parents, children with intellectual disability, uncooperative, or institutionalized were excluded.

\section{SAMPLE SIZE CALCULATION}

The sample size was estimated for correlation between two quantitative variables considering a bilateral $\alpha$ of $0.05, \beta$ of 0.10 , and a correlation of 0.3 , as suggested by Barbosa et al. [24], providing in total 113 dyads.

\section{VARIABLES}

The following groups of variables were considered from the preschooler:
- socio-demographic: sex (male/female), school grade (prekinder or kinder); all data were obtained from parents' report;

- oral health: history of caries of permanent (decayed, missing, and filled tooth [DMFT] index) and primary teeth (decayed, missing, and filled tooth [dmft]) were documented according to the $5^{\text {th }}$ edition of $\mathrm{WHO}$ guidelines [2]; severe caries was considered for three or more active decays;

- oral health-related quality of life (OHRQoL): it was measured using the SOHO-5 validated in Chilean population [23], which was answered by caregivers/ parents (parental version) and their child (child's version), and the ECOHIS was answered by caregivers/parents [17].

\section{ORAL HEALTH-RELATED QUALITY OF LIFE INSTRUMENTS}

SOHO-5: this instrument included child (SOHO-5c) and parent (SOHO-5p) version, both with seven items. The child version addresses difficulty eating, drinking, speaking, playing, sleeping, and smiling due to dental problems. Three response options were provided (no $=0$, a little $=1$, a lot $=2$ ) with the aid of a face scale. For the parent version, five response options were provided (not at all $=0$, a little $=1$, moderate $=2$, a lot $=3$, a great deal $=4$ ); a "don't know" option was included, which was not scored. The total score ranged from 0 to 14 in the child version (SOHO-5c) and from 0 to 28 in the parent version (SOHO-5p).

ECOHIS: this scale, which was answered by a parent, had 13 items distributed between the child impact (9 items) and family impact sections (4 items). The scores were calculated based on a five-point Likert scale, with response options ranging from "never" (0 points) to "very often" (4 points), and a "don't know" answer was included, which was not scored. The child impact section scores ranged from 0 to 36, and the family impact section from 0 to 16 , with a total score ranging from 0 to 50 [23].

The total score of both instruments were calculated by the sum of codes for each item, where higher scores denoting a greater negative impact on quality of life.

\section{DATA COLLECTION}

Collection of clinical and socio-demographic data, and the application of instruments were performed in the facilities of the school.

A single-trained examiner interviewed each child individually, without the presence of caregivers or other children to prevent their influence on the answers. Another single-trained examiner performed all clinical examinations, with a help of assistant. All equipment was previously sterilized. During the exam, the child laid on a school table.

The SOHO-5p and ECOHIS were self-administered to the parents/ caregivers during a parent-teacher meeting arranged for the purpose of this study. 
TABLE 1. Socio-demographic and clinical characteristics of children in $\mathrm{SOHO}-5$ and $\mathrm{ECOHIS}$

\begin{tabular}{|c|c|c|c|}
\hline Parameter & Female & Male & General \\
\hline \multicolumn{4}{|l|}{ Course $(n)$} \\
\hline Pre-kinder & 32 & 29 & 61 \\
\hline Kinder & 30 & 30 & 60 \\
\hline \multicolumn{4}{|l|}{$\mathrm{dmft}($ mean $\pm S D)$} \\
\hline Decay & $3.04 \pm 3.31$ & $2.68 \pm 2.65$ & $2.87 \pm 3.00$ \\
\hline Missed & $0.11 \pm 0.37$ & $0.02 \pm 0.13$ & $0.07 \pm 0.28$ \\
\hline Filled & $1.55 \pm 2.30$ & $2.05 \pm 2.47$ & $0.02 \pm 0.27$ \\
\hline \multicolumn{4}{|l|}{ DMFT (mean \pm SD) } \\
\hline Decay & $0.06 \pm 0.51$ & $0.03 \pm 0.18$ & $0.05 \pm 0.38$ \\
\hline Missed & $0.00 \pm 0.00$ & $0.00 \pm 0.00$ & $0.00 \pm 0.00$ \\
\hline Filled & $0.00 \pm 0.00$ & $0.05 \pm 0.39$ & $0.02 \pm 0.27$ \\
\hline SOHO-c (mean \pm SD) & $10.41 \pm 3.10$ & $9.76 \pm 1.48$ & $10.10 \pm 2.46$ \\
\hline SOHO-p (mean \pm SD) & $7.65 \pm 1.42$ & $7.47 \pm 0.91$ & $7.56 \pm 1.20$ \\
\hline ECOHIS (mean \pm SD) & $3.66 \pm 6.28$ & $4.64 \pm 7.05$ & $4.14 \pm 6.66$ \\
\hline Severe caries (\%) & 37.10 & 35.59 & 36.36 \\
\hline
\end{tabular}

\section{ETHICS}

This study was approved by the Research and Bioethics Committee of the Universidad Bolivariana (No. 001/2020), and was conducted in full accordance with the World Medical Association Declaration of Helsinki.

All the parents/caregivers agreed to participate by signing an informed consent. The survey was anonymous, and the information was used only for the purposes of this research.

\section{STATISTICAL ANALYSIS}

Data were tabulated in an Excel spreadsheet (Microsoft Corp., USA). The analysis of data was made using STATA 12/SE (StataCorp, TX, USA). Descriptive sta- tistics for distribution, mean, and standard deviation were made. Non-normal distribution was analyzed using Shapiro-Wilk test $(p<0.001)$; thus, non-parametric tests were used. Spearman's correlation coefficient was used to test the association between ECOHIS and SOHO-5 scores, as its dimensions, dmft index, and its components. Mann-Whitney $U$ test was applied to assess statistically significant differences in ECOHIS and SOHO-5 scores between the children with and without severe caries. Cohen's $d$ and $r$ were calculated for effect size determination. Based on Cohen's criteria, an effect size $<0.2$ was a small, 0.2 to 0.7 was a moderate, and $>0.7$ was considered a large difference. For all cases, statistical significance was set at $p<0.05$.

\section{RESULTS}

The sample consisted of 121 dyads, characterized in Table 1. Correlations between the SOHO-5 and ECOHIS, and their dimensions, are shown in Table 2.

A significant correlation was found between ECOHIS and teeth with caries $(\rho=0.2732 ; p=0.0024)$, filled teeth $(\rho=0.2015 ; p=0.0267)$, overall $\mathrm{dmft}(\rho=0.3758$; $p<0.001$ ), and between the SOHO-5 parent and overall $\mathrm{dmft}(\rho 0.1808 ; p=0.0472)$. Differences in the ECOHIS and SOHO-5 scores between children with and without severe caries are shown in Table 3.

\section{DISCUSSION}

In the present study, it was found that the SOHO-5p and ECOHIS were strongly correlated. Moreover, the SOHO-5p and ECOHIS were able to discriminate between preschoolers with and without severe caries. In contrast, the SOHO-5c was not correlated with the SOHO-5p, nor ECOHIS. In addition, the SOHO-5c did not discriminate between the presence and absence of severe caries among the sample.

We evaluated these two instruments' discriminative validity, as they are the only ones that have been validated in Chilean Spanish preschoolers [17, 23]. It is import-

TABLE 2. Responses to SOHO-5p, SOHO-5c, and ECOHIS questionnaires

\begin{tabular}{|l|c|c|c|}
\hline Factor & $\begin{array}{c}\text { SOHO-5 parent vs. ECOHIS } \\
\rho(\boldsymbol{p} \text {-value })\end{array}$ & $\begin{array}{c}\text { SOHO-5 child vs. SOH0-5 parent } \\
\rho \text { ( } \boldsymbol{p} \text {-value) }\end{array}$ & $\begin{array}{c}\text { SOHO-5 child vs. ECOHIS } \\
\rho(\boldsymbol{p} \text {-value })\end{array}$ \\
\hline Difficulty eating & $0.47(<0.001)$ & $0.05(0.54)$ & $0.09(0.35)$ \\
\hline Difficulty drinking & $0.04(0.66)$ & $0.10(0.26)$ & $0.16(0.07)$ \\
\hline Difficulty speaking & $0.15(0.09)$ & $-0.07(0.47)$ & $0.12(0.17)$ \\
\hline Difficulty playing & $0.20(0.02)$ & $0.17(0.07)$ & $-0.05(0.59)$ \\
\hline Difficulty sleeping & $0.38(<0.001)$ & $0.12(0.20)$ & $0.13(0.14)$ \\
\hline Avoiding smiling (due to pain) & $0.57(<0.001)$ & $-0.09(0.31)$ & $-0.05(0.56)$ \\
\hline Avoiding smiling (due to appearance) & $0.31(<0.001)$ & $<0.001(0.99)$ & $0.11(0.23)$ \\
\hline Total score & $0.65(<0.001)$ & $0.08(0.39)$ & $0.05(0.57)$ \\
\hline
\end{tabular}


TABLE 3. Discriminative validity of SOHO-5 and ECOHIS according to the presence or absence of severe caries

\begin{tabular}{|c|c|c|c|c|c|}
\hline Scale & $\begin{array}{c}\text { Without severe caries } \\
\text { Mean (SD) }\end{array}$ & $\begin{array}{c}\text { With severe caries } \\
\text { Mean (SD) }\end{array}$ & $p$-value & $r$ & Cohen's d \\
\hline \multicolumn{6}{|l|}{ SOHO-5 child } \\
\hline Difficulty eating & $1.34(0.64)$ & $1.31(0.67)$ & 0.68 & -0.01 & -0.03 \\
\hline Difficulty drinking & $1.21(0.57)$ & $1.18(0.54)$ & 0.80 & -0.02 & -0.05 \\
\hline Difficulty speaking & $1.21(0.52)$ & $1.09(0.42)$ & 0.08 & -0.11 & -0.24 \\
\hline Difficulty playing & $1.17(0.50)$ & $1.11(0.44)$ & 0.41 & -0.05 & -0.11 \\
\hline Difficulty sleeping & $1.23(0.56)$ & $1.06(0.33)$ & 0.05 & -0.15 & -0.34 \\
\hline Avoiding smiling (due to pain) & $2.88(0.43)$ & $2.84(0.48)$ & 0.52 & -0.04 & -0.10 \\
\hline Avoiding smiling (due to appearance) & $1.22(0.58)$ & $1.20(0.59)$ & 0.70 & -0.01 & -0.03 \\
\hline Total score & $10.26(9.67)$ & $9.82(9.15)$ & 0.21 & -0.08 & -0.18 \\
\hline \multicolumn{6}{|l|}{ SOHO-5 parent } \\
\hline Difficulty eating & $1.19(0.40)$ & $1.27(0.50)$ & 0.44 & 0.08 & 0.18 \\
\hline Difficulty drinking & $1.08(0.31)$ & $1.11(0.49)$ & 0.93 & 0.04 & 0.09 \\
\hline Difficulty speaking & $1.01(0.11)$ & $1.07(0.25)$ & 0.10 & 0.14 & 0.31 \\
\hline Difficulty playing & $1.01(0.11)$ & $1.14(0.23)$ & 0.005 & 0.25 & 0.55 \\
\hline Difficulty sleeping & $1.02(0.16)$ & $1.14(0.35)$ & 0.02 & 0.21 & 0.45 \\
\hline Avoiding smiling (due to pain) & $1.03(0.23)$ & $1.02(0.24)$ & 0.95 & 0.01 & 0.01 \\
\hline Avoiding smiling (due to appearance) & $1.05(0.22)$ & $1.09(0.25)$ & 0.41 & 0.07 & 0.16 \\
\hline Total score & $7.40(0.92)$ & $7.84(7.35)$ & 0.12 & 0.17 & 0.37 \\
\hline \multicolumn{6}{|l|}{ ECOHIS } \\
\hline \multicolumn{6}{|l|}{ Child impact section } \\
\hline Symptoms & $0.52(0.32)$ & $0.93(0.49)$ & 0.04 & 0.19 & 0.42 \\
\hline Function & $1.25(2.26)$ & $2.32(2.62)$ & 0.002 & 0.20 & 0.45 \\
\hline Psychological & $0.42(1.29)$ & $0.68(1.62)$ & 0.16 & 0.09 & 0.19 \\
\hline Child self-image/social interaction & $0.19(0.81)$ & $0.22(0.77)$ & 0.39 & 0.02 & 0.04 \\
\hline \multicolumn{6}{|l|}{ Family impact section } \\
\hline Parental distress & $0.42(1.06)$ & $0.66(1.42)$ & 0.35 & 0.09 & 0.20 \\
\hline Family function & $0.48(1.01)$ & $0.84(1.31)$ & 0.05 & 0.15 & 0.32 \\
\hline Total score & $3.27(6.14)$ & $5.66(7.31)$ & 0.005 & 0.17 & 0.37 \\
\hline
\end{tabular}

ant to highlight that the Chilean versions of SOHO-5c as the SOHO-5p and the Chilean version of ECOHIS reported a high Cronbach's $\alpha$.

Regarding the inability of the SOHO-5c to discriminate between preschoolers with and without severe caries, there are several issues. One reason may be due to the age of participants; in Chile, preschoolers generally range from 4 to 5 years old. It has been observed that only an initial understanding of time concept at the age of 5 is achieved, and these children experience difficulties understanding health concepts, which could affect the recall of past events [26]. Another reason could be their social context, as more than $50 \%$ of the Pablo Neruda School preschooler caregivers did not accessed higher education, and in some cases, they only completed elementary school. It has been well-described that social background play a major role in the comprehension [27].

To our knowledge, this is the second investigation that studied the discriminate validity of the SOHO-5 and ECOHIS, and similar results were obtained [24]. However, further research should include a wider population of preschoolers from different socio-economic backgrounds in order to determine the discriminative properties of the SOHO-5c. In addition, Zaror et al. suggested that the SOHO-5 would need more research in its reliability and interpretability [18]. The latter may be because previous studies did not analyze the SOHO-5c and SOHO-5p separately, whereas the SOHO-5c may underscore its global reliability.

The ECOHIS was the instrument with the strongest discriminative validity; it did not include preschoolers' 
participation, was user-friendly, with only 13 items. Moreover, the ECOHIS presented higher values regarding EMPRO (evaluating the measurement of patientreported outcomes) tool in overall score, conceptual and measurementmodel, reliability,validity, andinterpretability among OHRQoL instruments for preschoolers [18]. These features may be of relevance while choosing a tool for future OHRQoL research.

These significant results were based on statistics, which did not always assure a clinical relevance criterion. In fact, effect sizes for the ECOHIS/SOHO-5 and caries were small to moderate, but there was no large difference. Moreover, only total score for the ECOHIS showed a noticeable difference between the children with and without severe caries, but this was lesser than 3 points.

Among the limitations of the study is that we used $\mathrm{dmft}$ index instead of ICDAS, which does not measure the extension or severity of the lesion itself. Therefore, a patient classified as severe caries may have had 4 carries but with a scarce compromise, or a patient classified as no severe caries but with 2 active caries with a large compromise of the teeth involved. Another limitation is that the sample corresponded to a public school and most parents had a low household income; these two aspects were related with lower neuro-psychological maturity [27].

Among the application of this research in Chile is that the ECOHIS could be used by nursery teachers in caregivers to identify preschoolers that need dental care for prompting timely dental treatment. Although its acceptability by non-dental professionals has not been evaluated yet.

\section{CONCLUSIONS}

The ECOHIS and SOHO-5p were both significantly correlated with OHRQoL among preschoolers. Nevertheless, the SOHO-5c did not correlate with any of the variables studied, nor with the SOHO-p or ECOHIS.

The ECOHIS showed a greater discrimination with the oral health status of preschoolers, as measured by the presence of severe caries.

\section{CONFLICT OF INTEREST}

The authors declare no potential conflicts of interest with respect to the research, authorship, and/or publication of this article.

\section{References}

1. Locker D, Slade G. Oral health and the quality of life among older adults: the oral health impact profile. J Can Dent Assoc 1993; 59: $830-833,837-838,844$.

2. Allen F, Locker D. A modified short version of the oral health impact profile for assessing health-related quality of life in edentulous adults. Int J Prosthodont 2002; 15: 446-450.
3. Pahel BT, Rozier RG, Slade GD. Parental perceptions of children's oral health: the Early Childhood Oral Health Impact Scale (ECOHIS). Health Qual Life Outcomes 2007; 5: 6.

4. Atchison KA, Dolan TA. Development of the Geriatric Oral Health Assessment Index. J Dent Educ 1990; 54: 680-687.

5. Tsakos G, Blair YI, Yusuf H, Wright W, Watt RG, Macpherson LM. Developing a new self-reported scale of oral health outcomes for 5-year-old children (SOHO-5). Health Qual Life Outcomes 2012; 10: 62 .

6. Sischo L, Broder HL. Oral health-related quality of life: what, why, how, and future implications. J Dent Res 2011; 90: 12641270 .

7. Tesch F, Oliveira B, Leao A. Mensuracao do impacto dos problemas bucais sobre a qualidade de vida de criancas: aspectos conceituais e metodologicos. Cad SaudePublica 2007; 23: 2555-2564.

8. Wallander JL, Schmitt M, Koot HM. Quality of life measurement in children and adolescents: issues, instruments, and applications. J Clin Psychol 2001; 57: 571-585.

9. Sevenhuysen GP, Trumble-Waddell J. A new perspective on quality of life. J Clin Epidemiol 1997; 50: 231-232.

10. John MT, Hujoel P, Miglioretti DL, LeResche L, Koepsell TD, Micheelis W. Dimensions of oral-health-related quality of life. J Dent Res 2004; 83: 956-960.

11. Versloot J, Veerkamp JS, Hoogstraten J. Dental Discomfort Questionnaire: predicting toothache in preverbal children. Eur J Paediatr Dent 2004; 5: 170-173.

12. Mathur VP, Dhillon JK, Logani A, Agarwal R. Development and validation of oral health-related early childhood quality of life tool for North Indian preschool children. Indian J Dent Res 2014; 25: 559-566.

13. Li S, Veronneau J, Allison PJ. Validation of a French language version of an oral health impact questionnaire for infants: the ECOHIS. Health Qual Life Outcomes 2008; 6: 9.

14. Lee GH, McGrath C, Yiu CK, King NM. Translation and validation of a Chinese language version of the Early Childhood Oral Health Impact Scale (ECOHIS). Int J Paediatr Dent 2009; 19: 399-405.

15. Bordoni N, Ciaravino O, Zambrano O, Villena R, Beltran E, Squassi A. Early childhood oral health impact scale (ECOHIS). Translation and validation in spanish language. Acta Odontol Latinoam 2012; 25: 270-278.

16. Jabarifar SE, Golkari A, Ijadi MH, Jafarzadeh M, Khadem P. Validation of a Farsi version of the early childhood oral health impact scale (F-ECOHIS). BMC Oral Health 2010; 10: 4.

17. Zaror C, Atala-Acevedo C, Espinoza-Espinoza G, et al. Cross-cultural adaptation and psychometric evaluation of the early childhood oral health impact scale (ECOHIS) in chilean population. Health Qual Life Outcomes 2018; 16: 232.

18. Zaror C, Pardo Y, Espinoza-Espinoza G, et al. Assessing oral health-related quality of life in children and adolescents: a systematic review and standardized comparison of available instruments. Clin Oral Investig 2019; 23: 65-79.

19. Abanto J, Tsakos G, Paiva SM, Goursand D, Raggio DP, Bönecker M. Cross-cultural adaptation and psychometric properties of the Brazilian version of the scale of oral health outcomes for 5-year-old children (SOHO-5). Health Qual Life Outcomes 2013; 11: 16.

20. Rachmawati YL, Pratiwi AN, Maharani DA. Cross-cultural adaptation and psychometric properties of the Indonesia version of the scale of oral health outcomes for 5-year-old children. J Int Soc Prev Community Dent 2017; 7 (Suppl 2): S75-S81.

21. Abreu-Placeres N, Garrido LE, Féliz-Matos LE. Cross-cultural validation of the scale of oral health-related outcomes for 5-yearold-children with a low-income sample from the Dominican Republic. J Int Soc Prev Community Dent 2017; 7: 84-88.

22. Asgari I, Kazemi E. Cross-cultural adaptation of Persian version of scale of oral health outcomes for 5-year-old children. J Dent (Tehran) 2017; 14: 48-54.

23. Meza C, Cabello R, Rodríguez G, Faleiros S. Análisis comparativo de las encuestas de calidad de vida relacionada con salud oral: 
scale of oral health outcomes for five year old children (SOHO-5) versión en español y The early childhood oral health impact scale (ECOHIS) versión en español, en niños prescolares de la zona norte de la región Metropolitana" [undergraduate]. Universidad de Chile; 2020.

24. Fernandes IB, Ramos-Jorge J, Ramos-Jorge ML, et al. Correlation and comparative analysis of discriminative validity of the Scale of Oral Health Outcomes for Five-Year-Old Children (SOHO-5) and the Early Childhood Oral Health Impact Scale (ECOHIS) for dental caries. BMC Oral Health 2015; 15: 29.

25. Petersen PE, Baez R. World Health Organization. Oral Health Surveys: Basic Methods, $5^{\text {th }}$ ed. Paris: World Health Organization; 2013.

26. Rebok G, Riley A, Forrest C, et al. Elementary school-aged children's reports of their health: a cognitive interviewing study. Qual Life Res 2001; 10: 59-70.

27. Urzua A, Ramos M, Alday C, Alquinta A. Neuropsychological maturity in preschool children: psychometric properties of CUMANIN test. Ter Piscol 2010; 28: 13-25. 